\title{
Enhanced warming over the global subtropical western boundary currents
}

\author{
Lixin $\mathrm{Wu}^{1 \star}$, Wenju Cai ${ }^{2}$, Liping Zhang ${ }^{1}$, Hisashi Nakamura ${ }^{3}$, Axel Timmermann ${ }^{4}$, Terry Joyce ${ }^{5}$, \\ Michael J. McPhaden ${ }^{6}$, Michael Alexander ${ }^{7}$, Bo Qiu ${ }^{4}$, Martin Visbeck ${ }^{8}$, Ping Chang ${ }^{9}$ \\ and Benjamin Giese ${ }^{9}$
}

\begin{abstract}
Subtropical western boundary currents are warm, fast-flowing currents that form on the western side of ocean basins. They carry warm tropical water to the mid-latitudes and vent large amounts of heat and moisture to the atmosphere along their paths, affecting atmospheric jet streams and mid-latitude storms, as well as ocean carbon uptake ${ }^{1-4}$. The possibility that these highly energetic currents might change under greenhouse-gas forcing has raised significant concerns $^{5-7}$, but detecting such changes is challenging owing to limited observations. Here, using reconstructed sea surface temperature datasets and century-long ocean and atmosphere reanalysis products, we find that the post-1900 surface ocean warming rate over the path of these currents is two to three times faster than the global mean surface ocean warming rate. The accelerated warming is associated with a synchronous poleward shift and/or intensification of global subtropical western boundary currents in conjunction with a systematic change in winds over both hemispheres. This enhanced warming may reduce the ability of the oceans to absorb anthropogenic carbon dioxide over these regions. However, uncertainties in detection and attribution of these warming trends remain, pointing to a need for a long-term monitoring network of the global western boundary currents and their extensions.
\end{abstract}

The increase of carbon dioxide and other greenhouse gases in the atmosphere has been the major driver of surface warming of the Earth over the twentieth century, a warming that is projected to continue in the foreseeable future ${ }^{8}$. The oceans take up both heat and carbon dioxide, buffering this surface warming. The recent uptake of heat by the ocean ${ }^{9}$ has led to a significant increase in sea surface temperature (SST) in both the tropics and high latitudes, with strong warming in the tropical Indian Ocean, and weak warming over the deep-water-formation region in the high latitudes ${ }^{10,11}$.

Studies so far have focused on tropical warming patterns $s^{8,12-14}$ owing to their profound influence on atmospheric deep convection and global atmospheric teleconnections. However, an important region with some of largest air-sea fluxes of heat, moisture and carbon dioxide in the world's oceans is the convergence zone of extratropical western boundary currents. The poleward flowing warm/salty subtropical western boundary currents meet equatorward flowing cold/fresh counterparts from the subpolar ocean, separate from the coast and extend eastwards. These extensions form sharp thermal fronts fueling the mid-latitude storms that are of vital importance in the climate system. Associated with wintertime heat loss, carbon is absorbed and sequestrated into the ocean interior by the subduction and formation of mode water in these regions. Long air-sea equilibration timescales also lead to carbon sequestration downstream of the mode water formation regions.

Here we find a regionally accelerated warming since 1900 over the path of the subtropical western boundary currents in all the ocean basins that far exceeds the globally averaged surface ocean warming rate (Fig. 1). The global SST trends since 1900 are computed based on eight different datasets, including 'analysed' SST products that have been optimally interpolated or smoothed in both time and space (HadISST1, SODA, ERSSTv3b, Kaplanv2), 'unanalysed' SST datasets (HadSST2, Minobe/Maeda SST), and surface air temperature datasets (MOHMAT43, HadCRUT3; see Methods). Surface air temperatures (MOHMAT43, HadCRUT3) are independently measured, and therefore may serve as cross-validation for trends derived from SST datasets. In the tropical Pacific, the centre of action for the interannual El Niño/Southern Oscillation (ENSO) mode, the SST trend among these datasets differs significantly in sign and amplitude (Fig. 1), leaving a large uncertainty for the warming trend of the tropical Pacific ${ }^{15}$. However, in sharp contrast, all analysed SST datasets (HadISST1, SODA, ERSSTv3b, Kaplanv2) indicate a conspicuous warming trend over the path of the Pacific, Atlantic and Indian Ocean subtropical western boundary currents and their mid-latitude extensions in both hemispheres (Fig. 1a-d). The magnitude varies regionally and is dataset-dependent, with a range of $0.8-1.8^{\circ} \mathrm{C}$ per century, or about two to three times the rate of the globally averaged SST trend (Fig. 1i). The accelerated warming trends over the global subtropical western boundary currents are also evident in the unanalysed SST datasets (HadSST2, Minobe/Maeda SST; Fig. 1g,h) and surface air temperature datasets (MOHMAT43, HadCRUT3; Fig. 1e,f). In particular, both HadCRUT3 and HadSST2 reveal a nearly uniform warming rate of approximately $1.5^{\circ} \mathrm{C}$ per century over these western boundary current regions. Note that MOHMAT43, HadCRUT3, and HadSST2 data are independently measured based on different observational

\footnotetext{
${ }^{1}$ Physical Oceanography Laboratory, Ocean University of China, Qingdao 266003, China, ${ }^{2}$ CSIRO Marine and Atmosphere Research, Aspendale, Victoria 3195, Australia, ${ }^{3}$ Department of Earth, Planetary Science, University of Tokyo, Tokyo 113-8656, Japan, ${ }^{4}$ International Pacific Research Center, University of Hawaii, Honolulu, Hawaii 96822, USA, ${ }^{5}$ Physical Oceanography Department, Woods Hole Oceanographic Institution, Woods Hole, Massachusetts 02543, USA, ${ }^{6}$ National Oceanic and Atmospheric Administration/Pacific Marine Environmental Laboratory, Seattle, Washington 98115, USA, ${ }^{7}$ National Oceanic and Atmospheric Administration/Earth System Research Laboratory, Boulder, Colorado 80305, USA, ${ }^{8}$ Leibniz-Institut für Meereswissenschaften, IFM-GEOMAR, D-24105 Kiel, Germany, ${ }^{9}$ Department of Oceanography, Texas A\&M University, College Station, Texas 77843, USA. *e-mail: lxwu@ouc.edu.cn.
} 


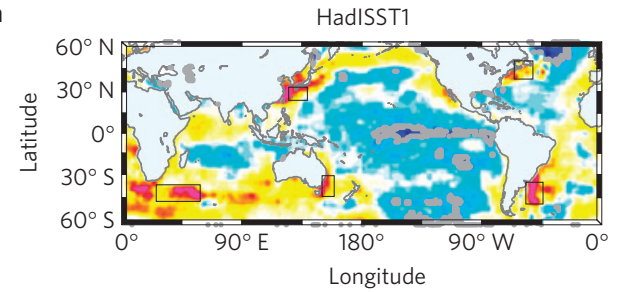

C
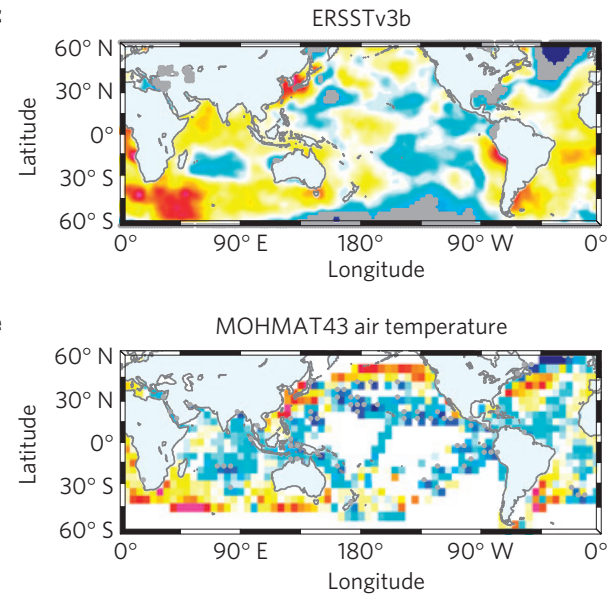

g

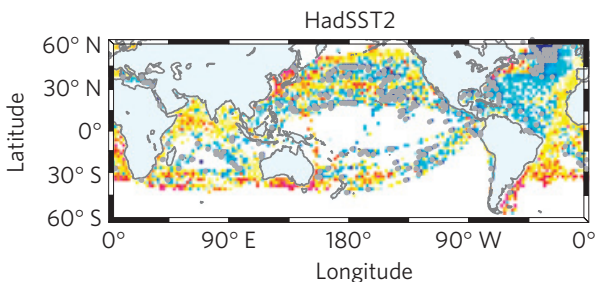

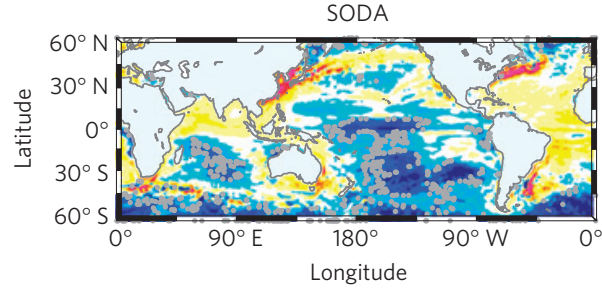

d
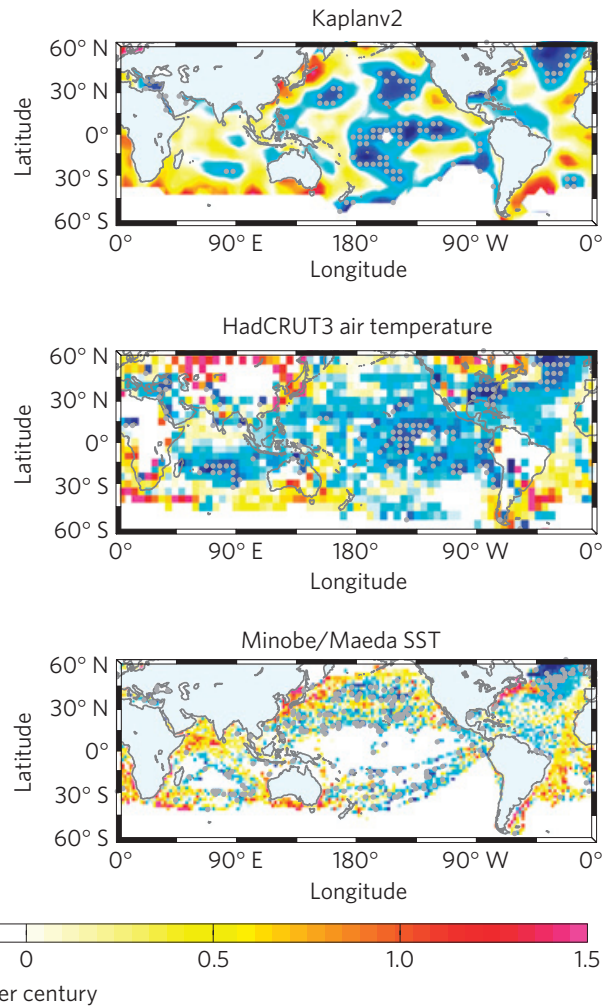

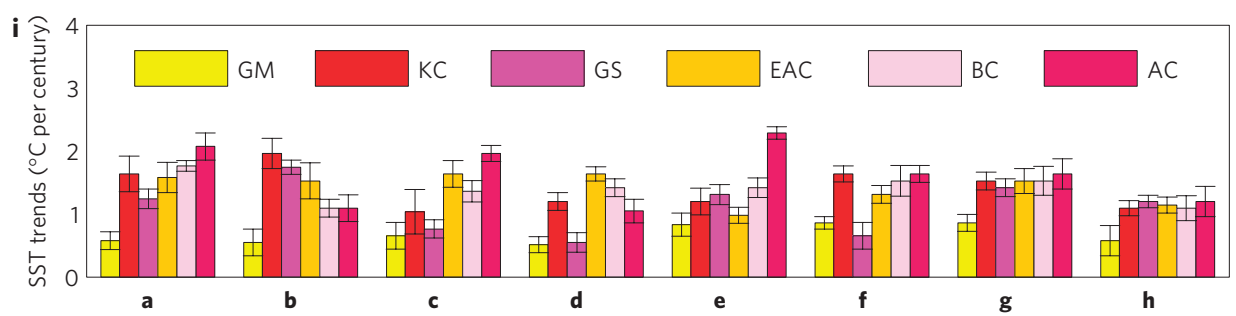

Figure 1 | Global SST trends over the 1900-2008 period. a-h, SST trends for various datasets. The corresponding global mean SST trend has been subtracted. White grid boxes denote insufficient data and grey boxes indicate trends that are not statistically significant at the $95 \%$ confidence level. $\mathbf{i}$, SST trends averaged over the mid-latitude extensions of the subtropical western boundary currents in each dataset (labels a-h stand for different datasets). Error bars denote the $95 \%$ confidence interval. Boundary current regions include the Kuroshio Current ( $\mathrm{KC} ; 25^{\circ} \mathrm{E}-150^{\circ} \mathrm{E}, 25^{\circ} \mathrm{N}-38^{\circ} \mathrm{N}$ ), the $\mathrm{Gulf} \mathrm{Stream}$ (GS; $75^{\circ} \mathrm{W}-45^{\circ} \mathrm{W}, 38^{\circ} \mathrm{N}-48^{\circ} \mathrm{N}$ ), the Eastern Australian Current (EAC; $150^{\circ} \mathrm{E}-165^{\circ} \mathrm{E}, 44^{\circ} \mathrm{S}-34^{\circ} \mathrm{S}$ ), the Brazil Current (BC; $58^{\circ} \mathrm{W}-35^{\circ} \mathrm{W}, 48^{\circ} \mathrm{S}-35^{\circ} \mathrm{S}$ ) and the Agulhas Current $\left(\mathrm{AC} ; 25^{\circ} \mathrm{E}-60^{\circ} \mathrm{E}, 45^{\circ} \mathrm{S}-35^{\circ} \mathrm{S}\right) . \mathrm{GM}$ is global mean.

Table 1 | Mean SST warming trends and standard deviations of global and regional subtropical western boundary currents over different periods ( ${ }^{\circ} \mathrm{C}$ per century) for eight different datasets.

\begin{tabular}{lllllll} 
Period & Global mean & Kuroshio Current & Gulf Stream & East Australian Current & Brazil Current & Aguhlas Current \\
\hline $1900-2008$ & $0.62 \pm 0.14$ & $1.29 \pm 0.30$ & $1.02 \pm 0.37$ & $1.30 \pm 0.23$ & $1.28 \pm 0.15$ & $1.40 \pm 0.40$ \\
$1900-1949$ & $0.60 \pm 0.18$ & $1.33 \pm 0.25$ & $2.31 \pm 0.15$ & $0.90 \pm 0.15$ & $1.13 \pm 0.18$ & $1.71 \pm 0.20$ \\
$1950-2008$ & $0.71 \pm 0.22$ & $1.10 \pm 0.31$ & $0.90 \pm 0.30$ & $1.37 \pm 0.23$ & $1.93 \pm 0.28$ & $1.31 \pm 0.42$
\end{tabular}

platforms or instruments ${ }^{15}$, so the consistency between different datasets suggests a robust process responsible for the accelerated warming over the global subtropical western boundary currents and their extensions. The magnitude of the warming trend varies with dataset but the ensemble mean of these eight datasets is about $1.2{ }^{\circ} \mathrm{C}$ per century over all the regions (Table 1 ). 

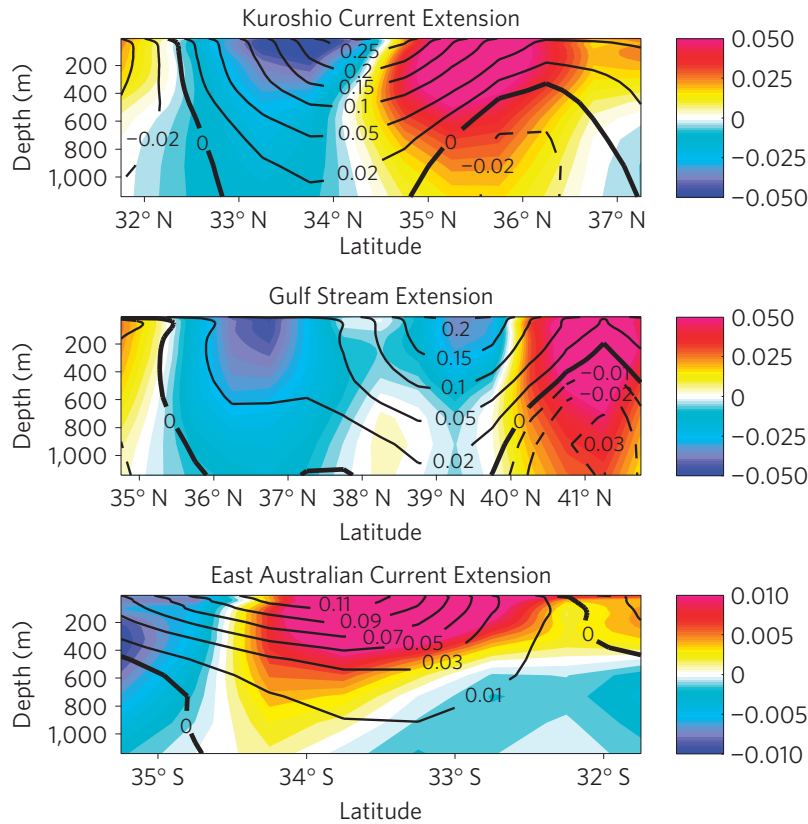

d
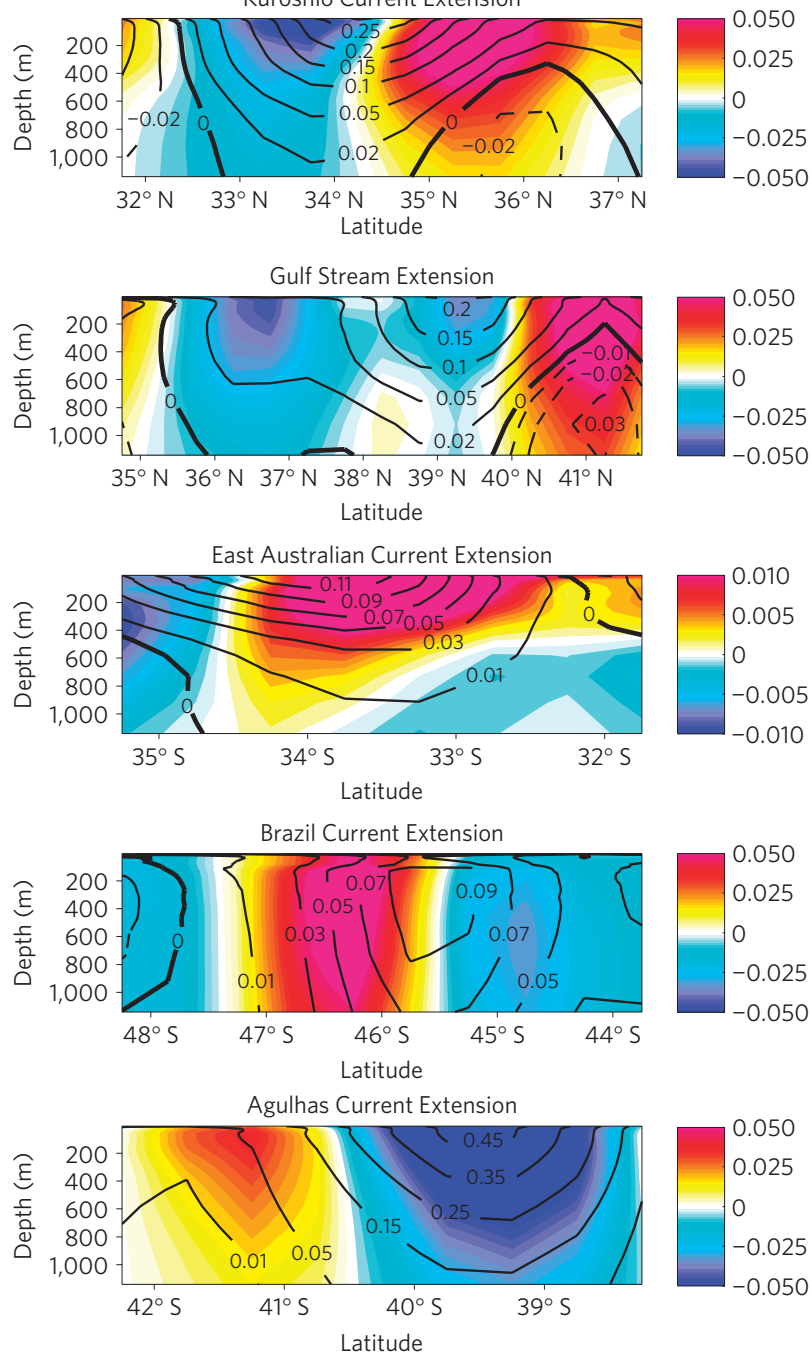
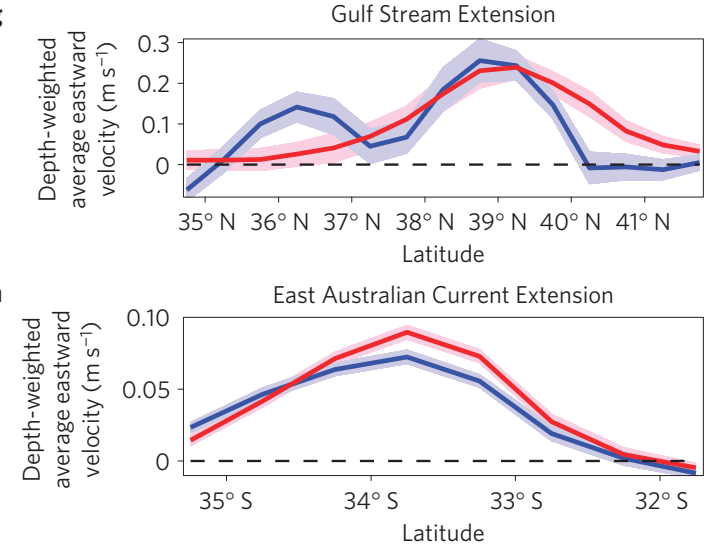

i

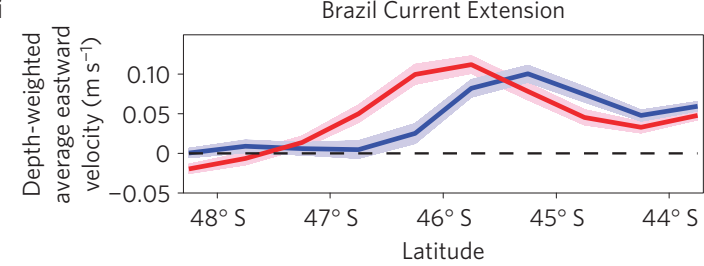

j

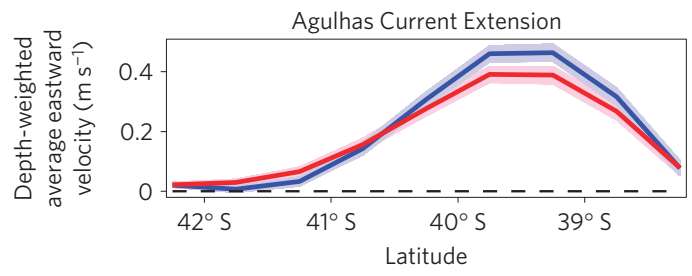

Figure 2 | Trends of eastward velocity across the extensions of the subtropical western boundary currents from SODA (1900-2008).

a-e, Depth-latitudinal profile of mean (contours) and trend (1900-2008, colour). Units for mean and trend are m s $\mathrm{and} \mathrm{m} \mathrm{s}^{-1}$ per century, respectively. $\mathbf{f}-\mathbf{j}$, Latitudinal distribution of depth-weighted average eastward velocity in upper $500-\mathrm{m}$. Red and blue curves denote mean \pm trend*N/2 $(\mathrm{N}$ is the length of data used for trend analysis), respectively. Shading indicates the $95 \%$ confidence interval of the trend. If the shading around the red and blue curves overlaps, the trend is not significant. The eastward velocity is zonally averaged over the Kuroshio Current $\left(140^{\circ} \mathrm{E}-180^{\circ}\right)$, the Gulf Stream $\left(290^{\circ} \mathrm{E}-320^{\circ} \mathrm{E}\right)$, the East Australian Current $\left(150^{\circ} \mathrm{E}-160^{\circ} \mathrm{E}\right)$, the Brazil Current $\left(295^{\circ} \mathrm{E}-320^{\circ} \mathrm{E}\right)$, and the Agulhas Current $\left(21.25^{\circ} \mathrm{E}-40^{\circ} \mathrm{E}\right)$, respectively.

The enhanced warming trends suggest a globally synchronous change of the subtropical western boundary currents over the past century. One important process that may lead to these enhanced oceanic warming trends is a poleward shift of the mid-latitude extensions of these boundary currents ${ }^{16-18}$. However, detecting human-induced changes in oceanic circulation has been severely hampered by a lack of direct long-term measurements. To assess the role of this process in affecting the warming trends, we use the newly developed century-long oceanic reanalysis product SODA and the Twentieth Century Atmospheric Reanalysis (20CRv2) product (see Methods). The evidence of a poleward shift of the subtropical western boundary currents is seen in the SODA reanalysis. Over the Kuroshio Extension, for example, the mean current axis, defined as the latitude of the maximum eastward velocity, is around $34^{\circ} \mathrm{N}$ with an eastward velocity of $25 \mathrm{~cm} \mathrm{~s}^{-1}$ (Fig. 2a), consistent with in situ observations ${ }^{19}$. The eastward velocity exhibits a dipolar trend pattern with an intensification on the northern flank and a weakening on the southern flank of the mean current axis (Fig. 2a). This indicates a poleward shift of the Kuroshio Current by about $0.8^{\circ} \pm 0.4^{\circ}$ over the past century (Fig. 2f) in association with the warming trend, suggesting a contribution from poleward warm water advection $^{17}$. A similar dipolar trend pattern is also detected along the Gulf Stream Extension (Fig. 2b), whose axis undergoes a poleward shift of $1.4^{\circ} \pm 0.8^{\circ}$ (Fig. $2 \mathrm{~g}$ ). In the Southern Hemisphere, the poleward axial shift is identified for the mid-latitude extensions of the Brazil Current (Fig. 2d,i), but less clear for the East Australian Current (Fig. 2c,h) and the Agulhas Current (Fig. 2e,j). Therefore, the enhanced warming over the Kuroshio Current, the Gulf Stream and the Brazil Current may be partly induced by the poleward axial shift of these western boundary currents.

Owing to the high nonlinearity of the western boundary currents and insufficient observations of both the winds and ocean temperatures during the early part of the twentieth century, some uncertainties remain in the poleward axial shift of the western boundary currents revealed by SODA. To further validate these results, we examine changes in the large-scale wind stress over the twentieth century in 20CRv2. Although the western boundary currents are not directly forced by the large-scale wind stress, the boundary between the subtropical and the subpolar gyres, in theory, is essentially set by the associated mid-latitude zero wind stress curl 

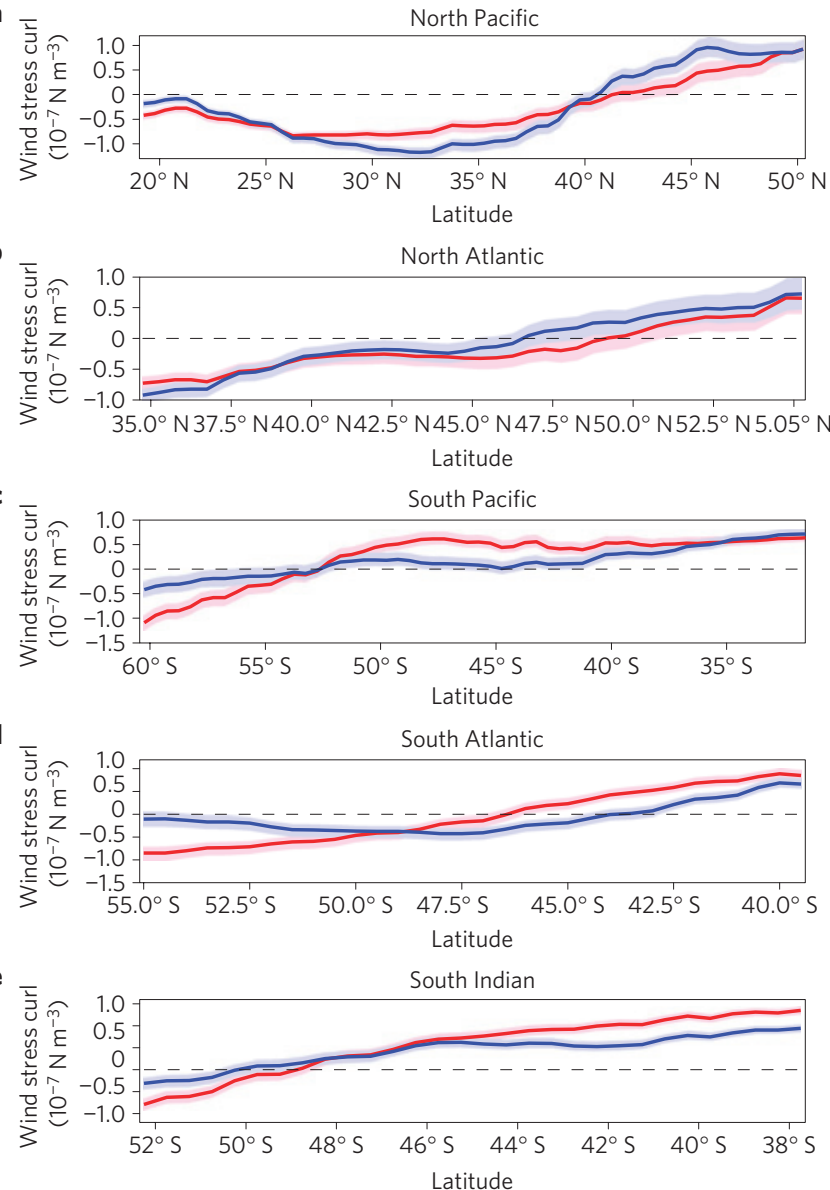

Figure 3 | Trends of zonally averaged wind stress curl over each ocean basin in 20CRv2 (1900-2008). Red and blue curves denote mean \pm trend* $N / 2$ ( $N$ is the length of data used for trend analysis), respectively. Negative (positive) values in the Northern (Southern) Hemisphere imply equatorward flow in the interior ocean that must be compensated by poleward flow in the western boundary. Shading indicates the $95 \%$ confidence interval of the trend. If the shading around the red and blue curves overlaps, the trend is not significant.

line. Therefore, the zero-curl line may be taken as a proxy of the jet latitude although in reality the axis of the mean jets does not necessarily follow the zero-curl line exactly. Over the past century, the zero-curl line averaged zonally across the basin has shifted poleward by about $3^{\circ} \pm 1.4^{\circ}$ over the North Pacific (Fig. 3a) and $2.5^{\circ} \pm 1.0^{\circ}$ over the North Atlantic (Fig. 3b). A poleward shift of the zonally averaged zero-curl line by about $2^{\circ} \pm 0.6^{\circ}$ is also apparent over the South Atlantic (Fig. 3d). The poleward shift tendency of the zero-curl line seems to be consistent with the sign of the poleward shift in the axis of the Kuroshio Current, the Gulf Stream and the Brazil Current, but the amplitudes are different. In general, the poleward shift of these boundary currents is about $1^{\circ}$ (Fig. 2), which is slightly smaller than that of the zero-curl line. Given the strong meridional temperature gradient in the convergence zones, the poleward migration of these boundary currents may lead to a large areal warming through advective changes in SST that are reinforced by strong air-sea heat exchanges. In the South Pacific and the South Indian Ocean, the latitude of the zonal extension of the boundary currents is set by the meridional extent of the coasts, and thus bears no relationship with the zero wind stress curl line (Fig. 3c,e). Therefore, the accelerated warming in these two regions may not be associated with the poleward shift of the western boundary current axes.
Another important process that may also potentially lead to these enhanced oceanic warming trends is an intensification of the western boundary currents, which can transport more warm tropical water into the cold mid-latitude oceans, augmenting the warming there. The changes in the amplitudes of the subtropical western boundary currents may be inferred from the changes in the surface wind stress curl, although nonlinear vorticity dynamics also plays a role. In each of the southern subtropical oceanic gyres, the anticyclonic wind stress curl has intensified over the past century (Fig. 3c-e), which may accelerate the interior equatorward flow and thus the poleward western boundary currents. It has been suggested that intensification of the East Australian Current (Fig. 2c,h), as manifested in an acceleration of the southern supergyre over the past decades, is caused by climate change-induced increases in the westerly wind $d^{5,18}$. In the Northern Hemisphere, however, the wind stress curl seems to have weakened or changed little in the subtropical North Pacific and the North Atlantic, respectively. Therefore, the enhanced warming over the western boundary currents in the Northern Hemisphere may not be associated with the changes in the amplitudes of the subtropical wind stress curl. There is a possibility that this connection works well at decadal timescales, but less so for long-term trends owing to additional buoyancy forcing effects in a warming climate.

The poleward shift of the zero-curl line and/or intensification of the subtropical wind stress curls are further supported by other atmospheric reanalysis products, despite some notable interproduct discrepancies (see Methods). Analysis of observational data over the past decades has also revealed a widening of the Hadley cells $^{20}$ and an associated poleward shift of westerly winds in both hemispheres ${ }^{21,22}$, which has been attributed to increasing greenhouse gas concentrations in the atmosphere. These atmospheric changes over recent decades are largely in the same direction as the centennial trends identified in our analysis of the surface wind stress curl. A poleward expansion of the oceanic subtropical gyres in both hemispheres has been supported by climate model simulations with increasing greenhouse-gas concentrations ${ }^{7}$.

Although the trends in the twentieth century are consistent with projections from climate models, an issue arises as to the extent to which the detected trends are associated with natural climate variability, particularly at decadal timescales. To address this issue, we assess the trends in two separate periods: 1900-1949 and 1950-2008. In the early period, enhanced warming can be found over the Kuroshio Current, the Gulf Stream and the Aguhlas Current regions in most of the datasets, whereas the warming over other subtropical western boundary current regions is marginal (Table 1 and Supplementary Fig. S1). The poleward shift is evident for the Kuroshio Current and the Brazil Current, but an equatorward shift, opposite to the long-term trend, is found for the Eastern Australia Current and the Aguhlas Current (Supplementary Fig. S2). These results are perhaps not surprising given that greenhouse-gas forcing in the early period is not strong, and some of the induced changes do not rise above the background of natural variability. In the later period, the enhanced warming is seen over all southern ocean western boundary current regions (Table 1 and Supplementary Fig. S3), consistent with the intensification trend of the southern subtropical western boundary currents (Supplementary Fig. S4) and the wind stress changes (Supplementary Fig. S5). However, both the Kuroshio Current and the Gulf Stream exhibit a trend towards an equatorward shift. For the Kuroshio Current, this equatorward shift is probably attributable to the mid-1970s North Pacific decadal climate shift ${ }^{16}$. Thus, in the later period, despite the stronger greenhouse-gas forcing, decadal variability could still substantially modulate the long-term trends in some ocean basins, such that the long-term trend can be different from decadal trends in both amplitude and sign (Supplementary Fig. S6). Nevertheless, for centennial timescale trends, influences from decadal variability 
diminish, and systematic enhanced warming is detected along the path of all western boundary currents, making it unlikely to be a reflection of decadal climate variability.

We conclude that the enhanced warming over the global subtropical western boundary currents in the twentieth century might be attributable to the poleward shift of their mid-latitude extensions and/or intensification in their strength. It should be noted that uncertainties remain large in terms of quantifying, detecting, and attributing the enhanced warming trends, owing to a lack of longterm observations of the western boundary currents and to varying algorithms used in SST reconstructions among reanalysis products. Some additional mechanisms, for example the enhanced upstream land warming, may also contribute to the warming over the western boundary current regions. The estimated errors of the trends presented here are also probably underestimated because they do not explicitly take into account uncertainties in observations, reconstruction algorithms, bias in data assimilations and so on. Nevertheless, the results highlight the importance of century-long datasets in detecting climate change signals. To detect future changes with confidence, a long-term monitoring network of western boundary current systems that builds on existing programmes ${ }^{23}$ is needed, particularly in regions of accelerated warming.

\section{Methods}

SST trends. Eight datasets are used for calculating global SST trends: Hadley Centre Sea Ice and SST version 1 (HadISST1; ref. 24); National Oceanic and Atmospheric Administration Extended Reconstructed SST version 2 (ERSSTv3b; ref. 25); Kaplan Extended SST version 2 (Kaplanv2; ref. 26); Simple Ocean Data Assimilation (SODA) SST product ${ }^{27}$; Hadley Centre SST version 2 (HadSST2; refs 28,29); night-time marine air temperature (NMAT) from Meteorological Office Historical Marine Air temperature version 4 (MOHMAT43; ref. 24); and air temperature from Hadley Centre/Climate Research Unit Temperature version 3 variance-adjusted (HadCRUT3; ref. 30). A detailed description of these datasets (except SODA) can be found in Deser et al..$^{15}$ and cited references. Among these datasets, MOHMAT43, HadCRUT3, and HadSST2 are independent, and others may differ in quality-control and bias correction procedures.

The linear trends are calculated from 1900 to 2008 monthly anomalies using the method of least-squares with statistical significance assessed using a Student's $t$-test. Following Deser $e t$ al..$^{15}$, we use a 24 -month per decade threshold as the sampling criterion, but results are not sensitive to this criterion. This restriction together with the consistency with independently measured marine air temperatures is used to assess the realism of the SST trends ${ }^{15}$.

Wind stress trends. The Twentieth Century Atmospheric Reanalysis product, designated as 20CRv2, contains the synoptic-observation-based estimate of global tropospheric variability spanning from 1871 to 2008 at 6-hourly temporal resolution and $2^{\circ}$ spatial resolution. The product is derived using observations of synoptic surface pressure and prescribing monthly SST and sea-ice distributions as boundary conditions for the atmosphere ${ }^{31}$. To assess the trends of the wind stress in the 20CRv2 atmospheric reanalysis dataset, we conducted an intercomparison with the National Center for Environmental Prediction and the National Center for Atmospheric Research (NCEP/NCAR) Reanalysis (1950-2009), the European Centre for Medium-Range Weather Forecasts (ECMWF) ERA40 Reanalysis (1957-2002), and the newly constructed WASWind (Wave and Anemometer-based Sea-surface Wind) dataset (1950-2009), in which the bias in the ship-based measurements of sea surface winds due to an increase in anemometer height has been corrected ${ }^{32}$. Over the past half century, the wind stress curl in all these data exhibits an upward trend in the southern subtropical oceans with the poleward-shifted zero line more pronounced over the Atlantic-Indian ocean sector (Supplementary Fig. S5). In the northern subtropics, the changes of the wind stress curl in the North Pacific are not significant in all these data, whereas in the North Atlantic the wind stress curl is intensified in 20CRv2, NCEP/NCAR and ERA40 but not in WASWind. The insignificant changes of the wind stress in the North Pacific may be partly attributable to the opposite effect of the mid-1970s North Pacific decadal climate shift, which leads to a cooling in the North Pacific and an equatorward migration of the zero wind stress curl line ${ }^{16}$. Indeed, the widening of the Hadley cells ${ }^{20}$ and associated poleward shift of westerly winds over the past three decades have been documented from both satellite observations and model simulations ${ }^{21,22}$. It should be noted the errors shown here are probably underestimated without explicitly taking into account uncertainties in different reconstructions. To further assess the robustness of the estimated trends, the ensemble mean and the standard deviation of trends derived from these four datasets are calculated. The ensemble mean exhibits an upward trend in global subtropical wind stress curl, except the subtropical North Pacific. The poleward shift of the zero-curl line is more evident in the South Atlantic and Indian Ocean sectors.
Oceanic current trends. The oceanic current trends are calculated based on the century-long SODA reanalysis product ${ }^{26}$, which is based on the Parallel Ocean Program (POP) ocean model with an average horizontal resolution of $0.4^{\circ}$ longitude $\times 0.25^{\circ}$ latitude and with 40 vertical levels. Temperature and salinity profiles are assimilated and include the recent release of the World Ocean Database 2009 (WOD09). Assimilation is carried out sequentially using a 10-day update cycle with model error covariances determined from a simulation that does not include assimilation. The surface boundary conditions are taken from 20CRv2.

To assess whether SODA captures variability of western boundary currents, we select two sections across the Kuroshio Current and the Gulf Stream where the transport has been routinely measured. Across the Pollution Nagasaki (PN line) section of the Kuroshio Current over the East China Sea, repeat hydrographic surveys have been conducted on a quarterly basis by the Japan Meteorological Agency since the mid-1950s. For the Gulf Stream, the transport of the Florida Current between Florida and the Bahamas near $27^{\circ} \mathrm{N}$ has been collected from calibration cruises and calibrated cable voltages since the early 1980s. The transports of the Kuroshio Current across the PN line, which is calculated from geostrophic balance, and the Florida Current are superimposed over these from SODA (Supplementary Fig. S7). The agreement is reasonably good, with a correlation of 0.6 and 0.65 (statistically significant at the $95 \%$ confidence level) for the Kuroshio Current and Florida Current during the observed period, respectively.

Received 6 May 2011; accepted 30 November 2011; published online 29 January 2012

\section{References}

1. Minobe, S., Kuwano-Yoshida, A., Komori, N., Xie, S-P. \& Small, R. J. Influence of the Gulf Stream on the troposphere. Nature 452, 206-209 (2008).

2. Kwon, Y-O. et al. Role of Gulf Stream, Kuroshio-Oyashio and their extensions in large-scale atmosphere-ocean interaction: A review. J. Clim. 23, 3249-3281 (2010).

3. Nakamura, H., Sampe, T., Tanimoto, Y. \& Shimpo, A. in Earth's Climate: The Ocean-Atmosphere Interaction Vol. 147 (eds Wang, C., Xie, S-P. \& Carton, J .A.) 329-346 (Geophysical Monograph Series, AGU, 2004).

4. Takahahi, T. et al. Climatological mean and decadal change in surface ocean p $\mathrm{CO}_{2}$ and net sea-air $\mathrm{CO}_{2}$ flux over the global oceans. Deep-Sea Res. 56, 554-577 (2009).

5. Roemmich, D. Super spin in the southern seas. Nature 449, 34-35 (2007).

6. Beal, L. M., De Ruijter, W. P. M., Biastoch, A., Zahn, R. \& SCOR/WCRP/IAPSO Working Group 136, On the role of the Aguhlas system in ocean circulation and Climate. Nature 472, 429-436 (2011).

7. Saenko, O. A., Fyfe, J. C. \& England, M. H. On the response of the oceanic wind-driven circulation to atmospheric $\mathrm{CO}_{2}$ increase. Clim. Dynam. 25, 415-426 (2005).

8. Meehl, G. et al. The WCRP CMIP3 multimodel dataset: A new era in climate change research. Bull. Am. Meteorol. Soc. 88, 1383-1394 (2007).

9. Levitus, S. et al. Anthropogenic warming of earth's climate system. Science 292, 267-270 (2001).

10. Sutton, R. \& Hodson, D. Climate response to basin-scale warming and cooling of the North Atlantic Ocean. J. Clim. 20, 891-907 (2007).

11. Xie, S. P. et al. Global warming pattern formation: Sea surface temperature and rainfall. J. Clim. 23, 966-986 (2010).

12. Cane, M. A. et al. Twentieth-century sea surface temperature trends. Science 275, 957-960 (1997).

13. Collins, M. \& CMIP Modelling Groups, El Niño-or La Niña like climate change? Clim. Dynam. 24, 89-104 (2005).

14. Vecchi, G. A. \& Soden, B. J. Global warming and the weakening of the tropical circulation. J. Clim. 20, 4316-4340 (2007).

15. Deser, C., Phillips, A. \& Alexander, M. Twentieth century tropical sea surface temperature trends revisited. Geophys. Res. Lett. 37, L10701 (2010).

16. Seager, R., Kushnir, Y., Naik, N. H., Cane, M. A. \& Miller, J. Wind-driven shifts in the latitude of the Kuroshio-Oyashio Extension and generation of SST anomalies on decadal timescales. J. Clim. 14, 4249-4265 (2001).

17. Marshall, J., Johnson, H. \& Goodman, J. A study of the interaction of the North Atlantic Oscillation with ocean circulation. J. Clim. 14, 1399-1421 (2001).

18. Cai, W. et al. The response of the Southern Annular Mode, the East Australian Current, and the southern mid-latitude ocean circulation to global warming. Geophys. Res. Lett. 32, L23706 (2005).

19. Joyce, T. M. \& Schmitz, W. J. Zonal velocity structure and transport in the Kuroshio Extension. J. Phys. Oceanogr. 18, 1484-1491 (1988).

20. Fu, Q., Johanson, C. M., Wallace, J. M. \& Reichler, T. Enhanced mid-latitude tropospheric warming in satellite measurements. Science 312, 1179 (2006).

21. Gillett, N. \& Thompson, D. Simulation of recent Southern Hemisphere climate change. Science 302, 273-275 (2003).

22. Lu, J., Vecchi, G. A. \& Reichler, T. Expansion of the Hadley cell under global warming. Geophys. Res. Lett. 34, L06805 (2007).

23. Cunningham, S. A. et al. Temporal variability of the Atlantic Meridional Overturning Circulation at $26.5^{\circ}$ N. Science 317, 935-938 (2007). 
24. Rayner, N. et al. Globally complete analyses of sea surface temperature, sea ice and night marine air temperature since the late nineteenth century. J. Geophys. Res. 108, 4407 (2003).

25. Smith, T. M. et al. Improvements to NOAA's historical merged land-ocean surface temperature analysis (1880-2006). J. Clim. 21, 2283-2296 (2008).

26. Kaplan, A. et al. Analyses of global sea surface temperature 1856-1991. J. Geophys. Res. 103, 18,567-18,589 (1998).

27. Giese, B. S. \& Ray, S. El Niño variability in simple ocean data assimilation (SODA), 1871-2008. J. Geophys. Res. 116, C02024 (2011).

28. Rayner, N. et al. Improved analyses of changes and uncertainties in sea surface temperature measured in situ since the mid-nineteenth century: The HadSST2 data set. J. Clim. 19, 446-469 (2006).

29. Minobe, S. \& Maeda, A. A 1 degree SST dataset compiled from IOCADS from 1850 to 2002 and Northern Hemisphere frontal variability. Int. J. Climatol. 25, 881-994 (2005).

30. Bohan, P., Kennedy, J., Harris, I., Tett, S. \& Hones, P. Uncertainty estimates in regional and global observed temperature changes: A new dataset from 1850. J. Geosphys. Res. 111, D12106 (2006).

31. Compo, G. P. et al. The Twentieth Century Reanalysis Project. Q. J. R. Meteorol. Soc. 137, 1-28 (2011).

32. Tokinaga, H. \& Xie, S-P. Wave and Anemometer-based Sea-surface Wind (WASWind) for climate change analysis. J. Clim. 24, 267-285 (2011).

\section{Acknowledgements}

This work is supported by China National Key Basic Research Project (2007CB411800) and National Natural Science Foundation Projects (40788002, 40930844, 40921004).

W.C. is supported by the Australian Climate Change Science program and the Southeast Australia Climate Initiative. H.N. is supported in part by the Japanese Ministry of Education, Culture, Sports, Science and Technology through Grant-in-Aid for Scientific Research on Innovative Areas \#2205 and by the Japanese Ministry of Environment through Global Environment Research Fund (S-5). M.J.M. is supported by the National Oceanic and Atmospheric Administration's Climate Program Office. PMEL Publication no. 3774 .

\section{Author contributions}

L.W. and W.C. contributed the central idea and wrote the initial draft of the paper. L.Z. performed data analyses. The remaining authors contributed to refining the ideas and to writing this paper.

\section{Additional information}

The authors declare no competing financial interests. Supplementary information accompanies this paper on www.nature.com/natureclimatechange. Reprints and permissions information is available online at http://www.nature.com/reprints. Correspondence and requests for materials should be addressed to L.W. 